\title{
Combination of Solamargine and Metformin Strengthens IGFBP1 Gene Expression Through Inactivation of Stat3 and Reciprocal Interaction Between FOXO3a and SP1
}

\author{
Qing Tang ${ }^{\mathrm{a}}$ Fang Zheng ${ }^{\mathrm{a}}$ JingJing $\mathrm{Wu}^{\mathrm{a}}$ QianXiao ${ }^{\mathrm{a}}$ Liuning $\mathrm{Li}^{\mathrm{b}}$ \\ Swei Sunny Hann ${ }^{a}$ \\ aLaboratory of Tumor Biology, ${ }^{b}$ Department of Medical Oncology, Guangdong Provincial Hospital of \\ Chinese Medicine, The Second Clinical Medical Collage, Guangzhou University of Chinese Medicine, \\ Guangzhou, China
}

\section{Key Words}

Nsclc $•$ Solamargine $\cdot$ Metformin $•$ Stat3 $\cdot$ FOXO3a $・$ IGFBP1 $・$ SP1

\begin{abstract}
Background/Aims: Solamargine, one natural photochemical component from traditional plants, has been shown to have anti-cancers properties. We previously showed that solamargine inhibited the growth of non-small-cell lung cancer (NSCLC) cells through suppression of prostaglandin E2 $\left(\mathrm{PGE}_{2}\right)$ receptor EP4 gene and regulation of downstream signaling pathways. However, the detailed mechanism underlying this, especially in combination of metformin, a known AMPK activator, still remained to be determined. Methods: Cell viability was measured using a 3-(4, 5-dimethylthiazol-2-yl)-2, 5-diphenyltetrazolium bromide (MTT) and colorimetric 5-bromo-2-deoxyuridine (BrdU) ELISA methods, respectively. Western blot analysis and immunohistochemistry were performed to examine the phosphorylation and protein expressions of signal transducer and activator of transcription 3 (Stat3), SP1, forkhead box O3a (FOXO3a), and insulin-like growth factor (IGF)-IGF binding protein 1 (IGFBP1). The expression of IGFBP1 mRNA was measured by quantitative real time PCR (qRT-PCR). Silencing of FOXO3a and IGFBP1 were examined by siRNA procedures. Exogenously expression of SP1, FOXO3a, and IGFBP1 were carried out by transient transfection assays. The promoter activity of IGFBP1 was tested using Secrete-Pair ${ }^{\mathrm{TM}}$ Dual Luminescence Assay Kit. A xenografted tumor model was used to further test the effect of solamargine in combining with metformin in vivo. Results: We further demonstrated that solamargine inhibited growth and induced cell cycle arrest in other NSCLC cell lines. Through mechanism-based approaches, we showed that solamargine decreased the phosphorylation of Stat3; In addition, solamargine induced FOXO3a, whereas reduced SP1 protein levels; all of which were abrogated in cells with overexpressed Stat3 gene.
\end{abstract}

Swei Sunny Hann

and Liuning Li
Laboratory of Tumor Biology and Department of Medical Oncology

No. 111, Dade Road, Guangzhou, Guangdong Province, (P. R. China)

Tel.+20-39318472, E-Mail hann2012@outlook.com/liliuning97@126.com 
Interestingly, there is interaction between FOXO3a and SP1. Moreover, solamargine increased mRNA, protein expression and promoter activity of IGFBP1, which was not observed in cells with overexpressed SP1 or with silenced FOXO3a genes. Finally, ablation of IGFBP1 expression by siRNA blocked the effect of solamargine on cell growth inhibition. More importantly, there was a synergy of combination of solamargine and metformin. Similar findings were also observed in vivo. Conclusion: Our results show that solamargine increases IGFBP1 gene expression through inactivation of Stat3, followed by regulation and reciprocal interaction of FOXO3a and SP1 in vitro and in vivo. This ultimately leads to suppression of human lung cancer cell growth. Moreover, this is a synergy of solamargine in combination with metformin in this process. This study unravels a novel mechanism underlying the anti-lung cancer effects of solamargine in combination of metformin, and suggests a potential new lung cancer associated therapy.

(C) 2017 The Author(s)

Published by S. Karger AG, Basel

\section{Introduction}

Lung cancer is one of life threatening malignancies with the highest incidence and mortality among cancer types worldwide. Non-small cell lung cancer (NSCLC) accounts for $80 \%$ to $85 \%$ of lung cancer cases, mostly diagnosed at advanced stages [1]. Although substantial efforts have been made using comprehensive treatment modalities, the 5-year survival rate still remains poor because of uncontrolled local or recurrent disease due to limited treatment efficacy and information available in understanding of the mechanisms of this illness $[1,2]$. Thus, the continuing efforts have been made in selecting other therapeutic options for the intervention of this malignancy to improve the quality of life and prolong the survival.

Signal transducer and activator of transcription 3 (Stat3), a member of the Stat family of transcription factors, is highly activated and expressed in several cancer types, and involved in several biological functions such as inflammation, proliferation, progression and metastasis in cancer [3-4]. Blockade of Stat3 has been shown to inhibit cell proliferation, induced apoptosis, and suppressed tumor formation $[5,6]$. Thus, targeting this signaling pathway could be a potential therapeutic approach for the prevention and treatment of cancer $[3,6,7]$.

Transcription factors of the forkhead box, class O (FOXO) family are crucial regulator of the cellular responses and play an important role in inhibition of tumor growth by influencing several downstream targets involved in cell cycle arrest, apoptosis, and proliferation [8]. Among the four members (FOXO1, FOXO3a, FOXO4 and FOXO6), FOXO3a is the more extensively studied. Numerous studies have demonstrated that FOXO3a regulated a wide range of biological functions including growth, differentiation, apoptosis, protection against oxidative stress, and metabolism [9-11]. Exogenously expression of FOXO3a has been shown to inhibit tumor growth in several cancer types $[12,13]$. These observations suggest that F0X03a functions as a tumor suppressor and may serve as a therapeutic target for the cancer treatment. However, studies have also observed that FOXO3a promotes cancer cell growth under oxidative stress [14] and serum deprivation condition [15]. Therefore, the true role of FOXO3a in cancer biology could be more complicated than we thought and warranted to be determined.

A number of studies have shown that natural compounds have anticancer properties. Solamargine, a plant derived steroidal glycoalkaloid, has been found to inhibit growth and induce apoptosis in several cancer types [16-20]. Solamargine reduced the growth of metastatic and primary melanoma cells via disrupting the intrinsic apoptosis pathway [20]. We previously found that solamargine reduced the proliferation of NSCLC cells through inhibition of prostaglandin E2 $\left(\mathrm{PGE}_{2}\right)$ receptor EP4, DNA methyltransferase 1 (DNMT1), and c-Jun expressions [21, 22]. However, the detailed mechanisms and potential benefits underlying the effects of solamargine in prevention and treatment of NSCLC still remain to be determined. 
The insulin-like growth factor (IGF)-IGF binding proteins (IGFBPs) play important roles in physiology and pathophysiology, such as development, metabolism, insulin sensitivity, mitochondrial protection, cell growth, differentiation and apoptosis [23-25]. Among six high-affinity binding proteins (IGFBP1 to 6), IGFBP1, which is abundantly expressed in the liver and decidualized endometrium [26], interacts with not only its canonical ligands IGF-I and IGF-II, but also other proteins, and involves in tumorigenesis, growth, invasion and metastasis of cancer [27, 28]. Report showed that excess of IGFBP1 inhibited growth of breast cancer cells via inhibition of IGF receptor 1 binding to IGFs [29]. High expression of IGFBP mRNA was strongly correlated with better survival in breast cancer mouse model [30]. We previously observed that ursolic acid, a natural pentacyclic triterpenoid, and emodin, one anthraquinones constituents derivative isolated from the roots of rheum palmatuma, inhibited growth of hepatocellular carcinoma and lung cancer cells through induction of IGFBP1 gene expression, suggesting tumor suppressing role of this molecule [31, 32]. However, conflicting results were observed in other cancer types, such as prostate $[33,34]$ and endometrial cancer [35] and others [36]. Thus, IGFBP1 may play dual roles depending upon the environmental content, cells examined, and agents exposed. More importantly, information and data available for the expression and function of IGFBP1 in lung cancer are limited, and the detailed mechanism underlying the anti-lung cancer effect of solamargine still remains to be elucidated.

In this study, we further explored the potential mechanism by which solamargine inhibited growth of NSCLC cells. We provided additional evidence showing that combination of solamargine and metformin, a drug for the treatment of type 2 diabetes, strengthened IGFBP1 gene expression through inactivation of Stat3, followed by regulation of FOXO3a and SP1 expressions in vitro and in vivo.

\section{Materials and Methods}

\section{Reagents and cell cultures}

Antibodies against the total Stat3 and phosphor-Stat3 (Tyr705), and FOX03a were purchased from Cell Signaling Technology Inc. (Beverly, MA, USA). The SP1, IGFBP1 and GAPDH antibodies were obtained from Abcam (Cambridge, MA, USA). MTT powder was purchased from Sigma Aldrich (St. Louis, MO, USA). FOXO3a and IGFBP1 small interfering RNAs (siRNAs) and Lipofectamine 3000 reagent were obtained from AB \& Invitrogen (Carlsbad, CA, USA). Solamargine was obtained from Chengdu Must Bio-technology Company (Chengdu, Sichuan, China), which was dissolved in water and diluted to the final concentration with culture medium before use. Other chemicals were purchased from Sigma Aldrich unless indicated (St. Louis, MO, USA). Human lung cancer cells (A549, PC9, H1299, H1650, H358, H1359 and H1975) were obtained from the Cell Line Bank at the Laboratory Animal Center of Sun Yat-sen University (Guangzhou, China) and the Chinese Academy of Sciences Cell Bank of Type Culture Collection (Shanghai, China), and have been authenticated for absence of Mycoplasma, genotypes, and morphology using a commercial available kit by Guangzhou Cellcook Biotech Co., Ltd (Guangzhou, China). Cells were cultured at $37^{\circ} \mathrm{C}$ in a humidified atmosphere containing 5\% CO2. The culture medium consisted of RPMI 1640 medium from Life Technologies (Carlsbad, CA, USA) supplemented with $10 \%$ (v/v) heat-inactivated fetal bovine serum (Invitrogen, Grand Island, NY), 100 mg/ml streptomycin and $100 \mathrm{U} / \mathrm{mL}$ penicillin (Sigma-Aldrich, St. Louis, MO). In addition, the medium of A549-luc cells was added Geneticin (G-418) Sulfate (200 $\mu \mathrm{g} / \mathrm{mL}$, Life Technologies, Carlsbad, CA, USA).

\section{Cell viability assay}

Cell viability was examined using the 3-(4, 5-dimethylthiazol-2-yl)-2, 5-diphenyltetrazolium bromide (MTT) assay as reported previously [37]. NSCLC cells $\left(5 \times 10^{3}\right.$ cells/well) seeded into 96 -well microtiterplate were treated with increasing concentrations of solamargine for up to $72 \mathrm{~h}$. Afterwards, $10 \mu \mathrm{L}$ of MTT (5 mg/ $\mathrm{ml}$ ) was added to each well and incubated for an additional $3 \mathrm{~h}$. After removing supernatant, the formazan product was dissolved by adding $150 \mu \mathrm{L}$ solvent dimethyl sulfoxide (DMSO) and optimal density was determined with $490 \mathrm{~nm}$ by ELISA reader (Perkin Elmer, Victor X5, Waltham, MA, USA). 


\section{Cellular Physiology Cell Physiol Biochem 2017;43:2310-2326 \\ \begin{tabular}{ll|l} 
and Biochemistry & $\begin{array}{l}\text { DOI: 10.1159/000484383 } \\
\text { Published online: October 27, } 2017\end{array}$ & $\begin{array}{l}\text { C } 2017 \text { The Author(s). Published by S. Karger AG, Basel } \\
\text { www.karger.com/cpb }\end{array}$ \\
\hline
\end{tabular}}

Quantitative real-time PCR

A quantitative real-time PCR (qRT-PCR) assay was performed to examine IGFBP1 transcripts. The primers used in this study were designed as follows: IGFBP1 forward 5'- TCACAGCAGACAGTGTGAGAC -3'; reverse 5'- CCCAGGGATCCTCTTCCCAT -3'; GAPDH forward 5'-AAGCCTGCCGGTGACTAAC-3'; reverse 5'- GCGCCCAATACGACCAAATC -3'. Total RNA (2 $\mu \mathrm{g})$ was reverse-transcribed using oligo-dT primers and Superscript II reverse transcriptase (Invitrogen, Grand Island, NY, USA) according to the manufacturer's instructions. Quantitative real-time PCR was performed in a $20 \mu \mathrm{L}$ mixture containing $2 \mu \mathrm{L}$ of the cDNA preparation, $10 \mu \mathrm{L} 2 \mathrm{X}$ SYBR Green Premix ExTaq (Takara, Japan), and $10 \mu \mathrm{M}$ primer on an ABI 7500 RealTime PCR System (Applied Biosystems, Grand Island, NY, USA). The PCR conditions were as follows: 30s at $95^{\circ} \mathrm{C}$, followed by 40 cycles of $5 \mathrm{~s}$ at $95^{\circ} \mathrm{C}$ and $34 \mathrm{~s}$ at $60^{\circ} \mathrm{C}$. Finally, $15 \mathrm{~s}$ at $95^{\circ} \mathrm{C}, 60 \mathrm{~s}$ at $60^{\circ} \mathrm{C}$ and $15 \mathrm{~s}$ at $95{ }^{\circ} \mathrm{C}$. Threshold values were determined for each sample/primer pair, the average and standard errors were calculated. Relative expression of IGFBP1 was calculated as $\Delta \mathrm{C}_{\mathrm{t}^{\prime}}$ measured by subtracting the $\mathrm{C}_{\mathrm{t}}$ of the GAPDH.

\section{Western blot analysis}

Western blot analysis was performed as described previously [37]. Equal amount of protein from whole cell lysates were solubilized in 2x SDS-sample buffer and separated by $10 \%$ SDS polyacrylamide gels, and electroblotted onto membranes (Millipore, MA, USA). Membranes were incubated with antibodies against phosphor-Stat3, total Stat3, FOXO3a, IGFBP1 and SP1 (1:1000). The membranes were later incubated with a secondary antibody conjugated to horseradish peroxidase (1:3000, Cell Signaling, Beverly, MA, USA). The membranes were washed again and transferred to freshly made ECL solution, and visualized using the enhanced chemiluminescence detection system (Immobilon Western; Millipore, Billerica, MA, USA). The signals were captured using the Gel Imagine System (Bio-Rad, Hercules, CA, USA).

\section{Treatment with FOXO3a and IGFBP1 siRNAs}

The detailed procedure was reported previously [37]. For the transfection procedure, cells were seeded in 6-well or 96-well culture plates in RPMI 1640 medium containing 10\% FBS (no antibodies), grown to $60 \%$ confluence, and FOXO3a, IGFBP1 and control siRNAs purchased from Life Technologies (Carlsbad, CA, USA), were transfected using Lipofectamine 3000 according to the manufacturer's instructions (Invitrogen, Waltham, MA, USA). After culturing for up to $30 \mathrm{~h}$, the cells were resuspended in fresh media in the presence or absence of solamargine for an additional $24 \mathrm{~h}$ for all other experiments.

\section{Transient transfection assays}

The detailed procedure was reported previously [38]. NSCLC cells were seeded at a density of $2 \times 10^{5}$ cells/well in 6-well dishes and grown to $50-60 \%$ confluence. For each well, control and wild type pEZXPG04-IGFBP1 promoter constructs (purchased from GeneCopoeia, Inc., Rockville, MD, USA) with or without $0.2 \mu \mathrm{g}$ of secreted alkaline phosphatase (SEAP) were co-transfected into the cells with the Lipofectamine 3000 Transfection Reagent. The preparation of cell extracts and measurement of luciferase activities were determined using the Secrete-Pair ${ }^{\text {TM }}$ Dual Luminescence Assay Kit (GeneCopoeia, Inc., Rockville, MD, USA). Luciferase activity (actual luminescence units) was normalized with SEAP within each sample. In the separate experiments, the desired N1-GFP or FOXO3a-GFP plasmid DNA, kindly provided by Frank M. J. Jacobs (Rudolf Magnus Institute of Neuroscience, Department of Pharmacology and Anatomy, University Medical Center, Utrecht, Netherlands) and was reported previously [39], the control (pcDNA3.1), SP1 overexpression pcDNA3.1Sp1/flu vector (kindly provided by Dr. Thomas E. Eling, National Institute of Environmental Health Sciences, USA) [40], the control (pCMV-6) and IGFBP1 expression vectors (IGFBP1pCMV6-AC-GFP) purchased from OriGene Technologies, Inc. (Rockville, MD, USA), at a final concentration of $2 \mu \mathrm{g} / \mathrm{mL}$ were transfected into the cells with the Lipofectamine 3000 reagent. Cells were incubated for $24 \mathrm{~h}$ at $37^{\circ} \mathrm{C}$, then treated with solamargine for the indicated time for all other experiments.

\section{In vivo experiments}

All experiment procedures related to animals were performed according to the guidelines for the care and use of laboratory animals by the Animal Care and Use Committee of Guangdong Provincial Hospital of Chinese Medicine and approved by the Committee of Animal Experimentation and the Ethic Committee of Guangdong Provincial Hospital of Chinese Medicine (the Ethics Approval Number 2014012). A total of 


\section{Cellular Physiology Cell Physiol Biochem 2017;43:2310-2326 \begin{tabular}{l|l|l|} 
DOI: 10.1159/000484383 & $\begin{array}{l}\text { C } 2017 \text { The Author(s). Published by S. Karger AG, Basel } \\
\text { www.karger.com/cpb }\end{array}$
\end{tabular} \\ Tang et al.: Combination of Solamargine and Metformin Strengthens IGFBP1 Gene Expression}

36 eight-week-old female nude mice obtained from Guangdong Provincial Research Center for Laboratory Animal Medicine (Foshan, Guangdong, China) were maintained at the Animal Center of Guangdong Provincial Hospital of Chinese Medicine in a specific pathogen-free environment with food and water provided. A549 NSCLC cells carrying luciferase report gene (A549-Luc, obtained from the Guangzhou Land Technology

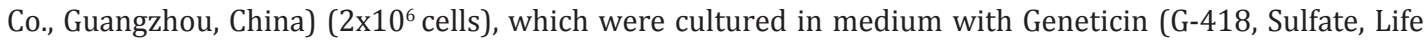
Technologies, USA) at concentration of $200 \mu \mathrm{g} / \mathrm{mL}$, were injected subcutaneously in the upper hind limb of mice. Xenografts were expected to grow for $8^{\text {th }}$ days when the initial measurement was available. Mice were randomly divided into control, metformin $(250 \mathrm{mg} / \mathrm{kg}$, obtained from Enzo Biochem, NY, USA), solamargine (6 mg/kg), and metformin (250 mg/kg) plus solamargine (6 mg/kg groups), which given once a day via gavages and intraperitoneal injection for up to 27 days (n=9/group), which were based on other and our previous studies [22, 41, 42].

Next, mice were anesthetized by inhalation of $2 \%$ isoflurane. The substrate D-luciferin (Caliper Life Sciences, Hopkinton, MA, USA) was injected into the peritoneal cavity with a dose of $150 \mathrm{mg} / \mathrm{kg}$ in approximately $100 \mu \mathrm{L}$. The intensity of bioluminescence imaging (BLI) signal was determined using the IVIS-200 Imaging System (Xenogen/Caliper, Alameda, CA, USA). The formula for an oblong sphere: volume $=\left(\right.$ width $^{2} \times$ length $)$ were used for measuring tumor volume. Quantification of bioluminescence was reported as photons/sec. The body weights of the mice were measured once a week. All mice were sacrificed on day 27 in accordance with the Guide for the Care and Use of Laboratory Animals. At the end of the experiments, xenografted tumors were isolated from individual animals and the corresponding lysates were processed and detected FOXO3a, SP1 and IGFBP1 by Western blot with the indicated antibodies.

\section{Immunohistochemistry (IHC)}

Immunohistochemical assay was used to determine SP1, FOXO3a and IGFBP1 protein expressions in xerografted tumors, which were fixed in $10 \%$ formaldehyde for $24 \mathrm{~h}$ and then embedded with paraffin. The specimens were cut into $5 \mu \mathrm{m}$ sections and antigenic retrieval was performed in citric acid buffer (pH 6.0). Sections were incubated with primary antibody against IGFBP1 (dilutions of 1:50, Abcam, UK), SP1, FOXO3a (dilutions of 1:100, Cell Signaling Technology, USA) at $4{ }^{\circ} \mathrm{C}$ overnight, followed by incubating with second antibody (Maixin Biotech. Co. Ltd, Fuzhou, China) for 30 mins. Detection was performed using 3, 3'-diaminobenzidine (DAB) chromogen kit (Maixin Biotech. Co. Ltd, Fuzhou, China). Pictures were taken under 200× magnification by BX53+DP72 Microscope (Olympus Corporation, Tokyo, Japan). The immunostaining was evaluated by Image-Pro Plus 6.0 image analysis software (Media Cybernetics, Inc. Sliver Spring, MD, USA) in at least five random high-power fields.

\section{Statistical analysis}

Statistical analysis was carried out using GraphPad Prism version 5.04 for Windows (GraphPad Software, La Jolla, CA, USA). All data are expressed as mean \pm SD. Differences between groups were assessed by one-way ANOVA and significance of difference between particular treatment groups was analyzed using Dunnett's multiple comparison tests. Asterisks showed in the figures indicate significant differences of experimental groups in comparison with the corresponding control one. In all analyses, $P$-values $<0.05$ were considered as statistically significant

\section{Results}

\section{Solamargine inhibited cell growth and induced cell arrest in lung cancer cells}

We previous showed that solamargine inhibited growth of human lung cancer A549 cells [21]. In the current study, we further assessed the relative contribution of inhibition affected by solamargine. As expected, we observed that, compared with the untreated control cells, solamargine significant inhibited growth of NSCLC PC9 cells using MTT assays (Fig. 1A) and in both A549 and PC9 cells using colorimetric BrdU ELISA methods (Fig. 1B). The similar results were also observed in other NSCLC cell lines as determined by MTT assays (Fig. 1C). The results above further indicated the anti-lung cancer effects of solamargine. Moreover, we found that combination of solamargine and metformin, a known AMPK activator and drug for the treatment of type 2 diabetes which has been shown to have anti-tumor effects [43], enhanced the effect of cell growth inhibition (Fig. 1D) and further increased cell cycle 
Fig. 1. Solamargine inhibited cell growth and induced cell arrest in lung cancer cells.A, PC9 cells were stimulated with indicated concentrations of solamargine (SM) for up to $72 \mathrm{~h}$. The cells were collected and processed for MTT assay as described in the Materials and Methods section. B, A549 and PC9 cells were treated with indicated concentrations of SM for 48 $h$, followed by processing for measuring cell growth as determined by colorimetric BrdU ELI-

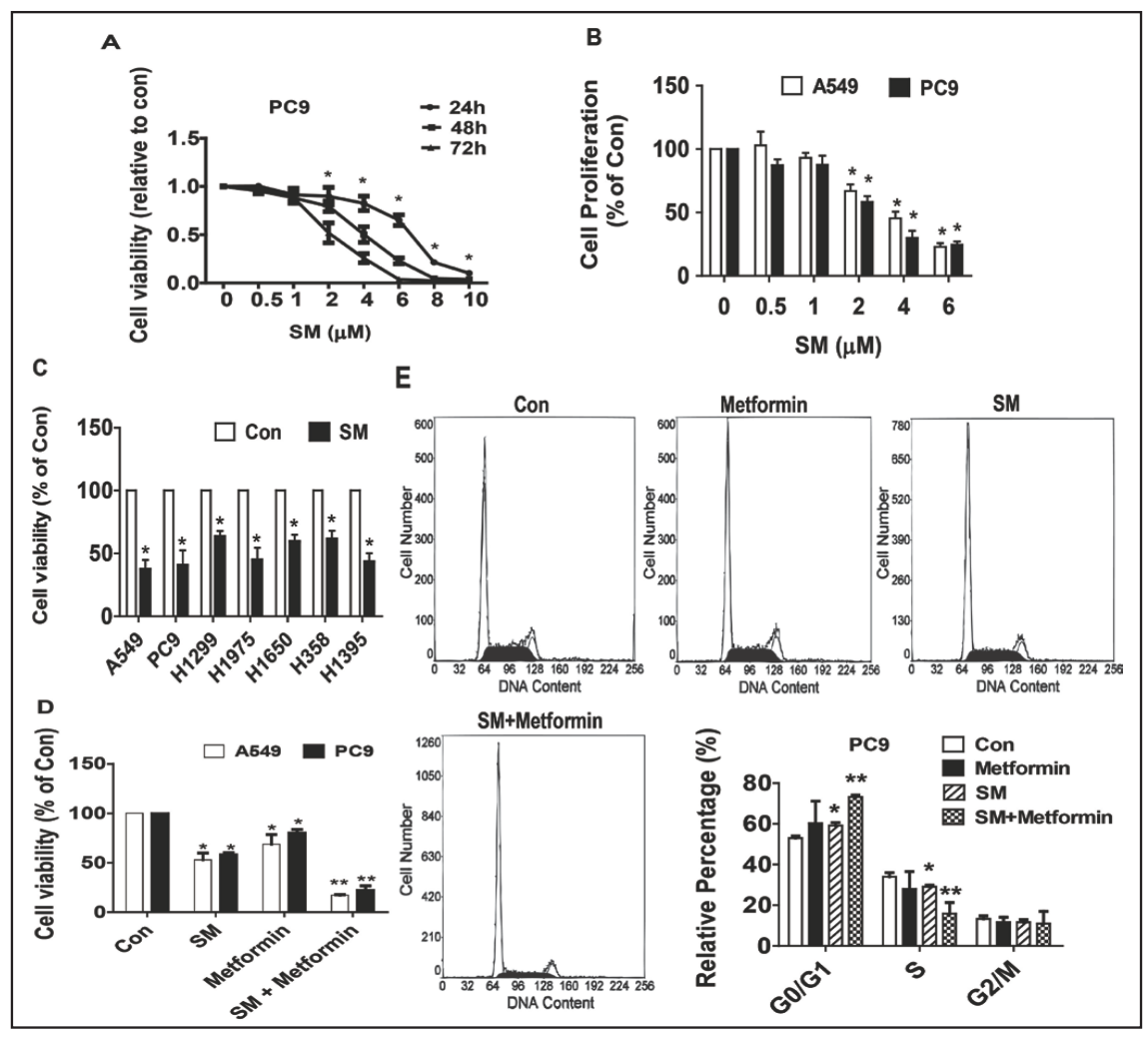
SA methods described in the Materials and Methods section. C, NSCLC cell lines indicated were treated with SM (6 $\mu \mathrm{M})$ for $48 \mathrm{~h}$, followed by measuring cell viability by MTT assay. D, A549 and PC9 cells were treated with SM ( $6 \mu \mathrm{M})$ and metformin $(5 \mathrm{mM})$ for up to $48 \mathrm{~h}$, followed by measuring the cell viability by MTT assays. E, A549 cells were treated with SM $(6 \mu \mathrm{M})$ in the presence or absence of metformin $(5 \mathrm{mM})$ for up to $48 \mathrm{~h}$. Afterwards, the cells were collected and processed for analysis of cell cycle distribution by flow cytometry. The percentages of the cell population in each phase (G0/G1, S and G2/M) were assessed by Multicycle AV DNA Analysis Software. Values are given as the mean $\pm S D$, from 3 independent experiments performed in triplicate. *indicates a significant difference from the control group $(\mathrm{P}<0.05)$. ${ }^{* *}$ Indicates significance of combination treatment as compared to $\mathrm{SM}$ alone $(\mathrm{P}<0.05)$.

arrest at G0/G1 phases (Fig. 1E) as compared to that in the solamargine alone. This implied potential synergy in this process.

\section{Solamargine increased phosphorylation of Stat3 in lung cancer cells}

To gain insight into the potential signaling pathways involving in solamargine- inhibited growth of lung cancer cells, we then set up to examine the effect of solamargine on Stat3 signaling. Stat3 is recognized as a transcription factor that modulates the transcription of a variety of genes that have been involved in important biological functions including cell proliferation, differentiation, survival, angiogenesis, immune response and cancer biology [9-11]. We found that solamargine $(6 \mu \mathrm{M})$ decreased phosphorylation of Stat3, while it had no effect on total Stat3 protein expression in A549 and PC9 cells (Fig. 2A). Interestingly, the combination of solamargine and metformin enhanced the effect of inactivation of Stat 3 in A549 and PC9 cells (Fig. 2B).

Solamargine elevated FOXO3 protein and reduced SP1 protein expression through inactivation of Stat3

We also searched for the potential downstream effectors of Stat3 that regulated by solamargine. We first assessed the effect of solamargine on transcription factors FOXO3a and 
Fig. 2. Solamargine increased phosphorylation of Stat3 in lung cancer cells. A, A549 and PC9 cells were exposed to increased concentrations of SM for $24 \mathrm{~h}$, followed by measuring the phosphorylation and protein expression of Stat3 by Western blot. The bar graphs represented the mean \pm SD of p-Stat 3 , Stat 3 / GAPDH of three independent experiments. B, A549 and PC9 cells were treated with SM $(6 \mu \mathrm{M})$ and metfor$\min (5 \mathrm{mM}$ ) for up to $24 \mathrm{~h}$. afterwards, the phosphorylation of Stat3 was measured by Western blot. The bars represented the mean \pm SD of p-Stat3/GAPDH at least three independent experiments for each condition. *Indicates significant difference as compared to the untreated control group $(\mathrm{P}<0.05)$; ${ }^{* *}$ Indicates significance of combination treatment as compared to SM alone $(\mathrm{P}<0.05)$.

SP1 that linked to the Stat3 signaling and regulated a number of cellular functions involving in tumorigenesis, tumor progression, apoptosis, and metastasis [44, 45]. We showed that solamargine elevated FOXO3a protein levels in A549 and PC9 cells (Fig. 3A). On the contrary, solamargine decreased SP1 protein expression (Fig. 3B). As expected, the combination of solamargine and metformin enhanced the effect of reduction of SP1 and induction of FOXO3a proteins (Fig. 3C-D). Intriguingly, we also showed that exogenously expressed Stat3 overcame the effect of solamargine on FOXO3a and SP1 protein expressions (Fig. 3E). Interestingly, we observed that, while exogenously expressed FOXO3a had little effect on solamarginedecreased SP1 protein, overexpressed SP1 significantly resisted the effect of solamargine on FOXO3a protein expression, suggesting SP1 may be upstream of FOXO3a in this process (Fig. 3F-G). Together, the results above implied that inactivation of Stat3 was required in mediating the effects of solamargine -reduced SP1 and -induced FOXO3a proteins.

\section{Solamargine induced expression of IGFBP1 protein, $m R N A$, and promoter activity}

To further explore the potential downstream targets that mediated the anti-lung cancer effect of solamargine, we investigated the role of IGFBP1, which was secreted from the liver and had a protective role in the development of cancer $[23,24,46]$. We showed that solamargine increased not only protein and mRNA levels of IGFBP1 as determined by Western Blot and qRT-PCR (Fig. 4A-B), but also IGFBP1 promoter activity as determined by SecretePair $^{\mathrm{TM}}$ Dual Luminescence Assay Kit (Fig. 4C). Of note, the combination of solamargine and metformin enhanced IGFBP1 protein expression (Fig. 4D).

Interaction between FOXO3a and SP1 contributed to the induction of IGFBP1 expression by solamargine

To explore the functional relevance of transcriptional factors that involved in the upregulation of IGFBP1 expression, we further investigated the role of FOXO3a and SP1. 


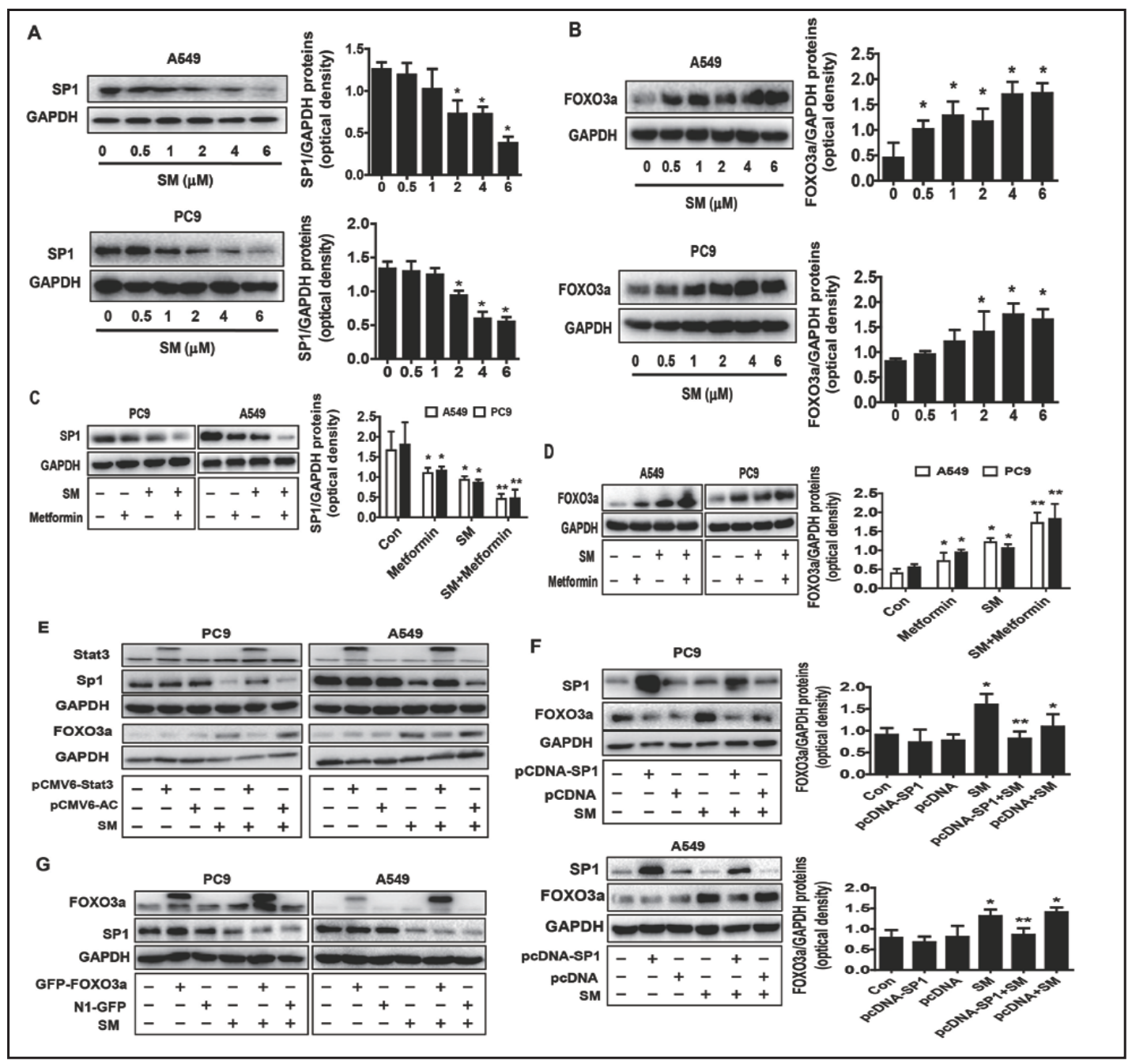

Fig. 3. Solamargine elevated FOXO3 and reduced SP1 protein expressions through inactivation of Stat3. A-B, A549 and PC9 cells were exposed to increased concentrations of SM for $24 \mathrm{~h}$, followed by measuring the protein expressions of SP1 and FOXO3a by Western blot. C-D, Cellular protein was isolated from A549 and PC9 cells treated with SM $(6 \mu \mathrm{M})$ in the presence or absence of metformin (5 mM) for up to $24 \mathrm{~h}$. Afterwards, the expression of SP1 and FOXO3a proteins was detected by Western blot. E, A549 and PC9 cells were transfected with the control or Stat3 expression vectors for $24 \mathrm{~h}$ before exposing to SM for an additional 24 h. Afterwards, Stat3, SP1, FOXO3a protein expressions were determined by Western blot. F-G, A549 and PC9 cells were transfected with either the control or SP1 (F), or FOXO3a (G) expression vectors for $24 \mathrm{~h}$ before exposing to SM for an additional $24 \mathrm{~h}$. Afterwards, SP1 and FOXO3a protein expressions were determined by Western blot. *Indicates significant difference as compared to the untreated control group $(\mathrm{P}<0.05)$; $* *$ Indicates significance of combination treatment as compared to SM alone $(\mathrm{P}<0.05)$.

Report showed that IGFBP1 promoter contained FOXOs and SP1 binding sites and that FOXOs and SP1 could regulate IGFBP1 gene expression and its downstream signaling [4749]. Importantly, we found that either silencing of FOXO3a or exogenously expressed SP1 overcame the effect of solamargine on IGFBP1 expression in both A549 and PC9 cells (Fig. $5 A-B)$. Conversely, overexpression of FOXO3a enhanced the effect of solamargine on IGFBP1 expression (Fig. 5C). Together, the above results indicated that FOXO3a and SP1, acting as upstream signals of IGFBP1, interacted with each other to regulate the expression of IGFBP1 in NSCLC cells. We further characterized the ability of IGFBP1 to regulate cell growth and regulation of Stat3. While overexpression of IGFBP1 had no effect on feedback regulation of 
Fig. 4. Solamargine induced expression of IGFBP1 protein, mRNA and promoter activity. A-B, A549 and PC9 cells were exposed to increased concentrations of SM for $24 \mathrm{~h}$, followed by measuring the protein and mRNA expressions of IGFBP1 by Western blot and qRT-PCR, respectively. C, A549 and PC9 cells were transfected with a wild type human IGFBP1 promoter reporter construct ligated to luciferase reporter gene and an internal control secreted alkaline phosphatase for $24 \mathrm{~h}$, fol-

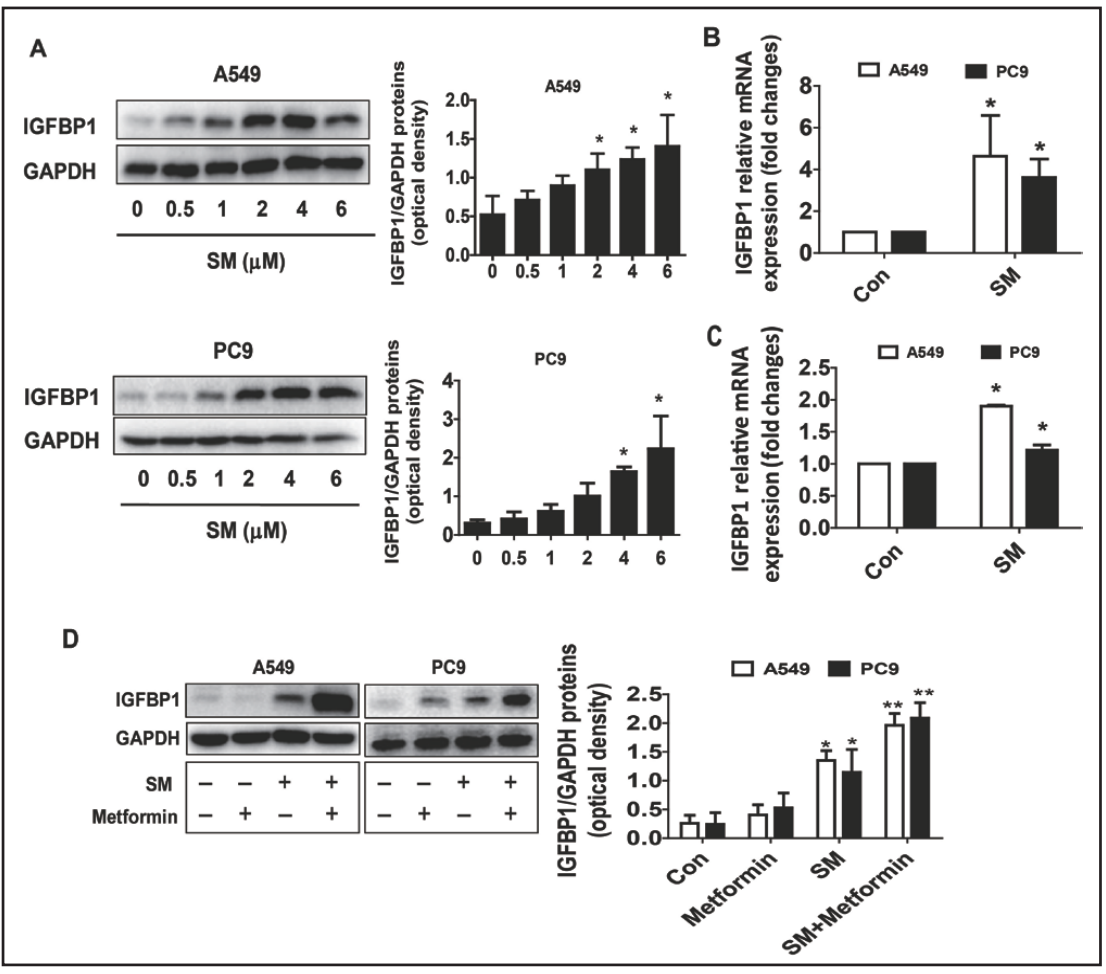
lowed by treating with SM for an additional $24 \mathrm{~h}$. Afterwards, the promoter activities were determined using the Secrete-Pair Dual Luminescence Assay Kit as described in the Materials and Methods section. D, Cellular protein was isolated from A549 and PC9 cells treated with SM (6 $\mu \mathrm{M})$ in the presence or absence of metformin ( $5 \mathrm{mM}$ ) for up to $24 \mathrm{~h}$. Afterwards, the expression of IGFBP1 protein was detected by Western blot. The bar graphs represented the mean \pm SD of IGFBP1/GAPDH of three independent experiments. *Indicates significant difference as compared to the untreated control group $(\mathrm{P}<0.05)$; ${ }^{* *}$ Indicates significance of combination treatment as compared to SM alone $(\mathrm{P}<0.05)$.

Stat3 activation (Fig. 5D); it resisted the effect of solamargine on cell growth inhibition (Fig. $5 \mathrm{E})$ implying a critical role of IGFBP1 induction in this process.

\section{In vivo anti-tumor efficacy of solamargine in nude mice model}

In order to prove the results in vitro, we tested the effect of solamargine on lung cancer xenografts in nude mice model. Luciferase-expressing A549 cells (A549-Luc) were injected subcutaneously in nude mice followed by intraperitoneal injection of D-luciferin. Mice bearing xenografted tumors were treated with control, metformin, solamargine alone, and combination of metformin and solamargine via garages (metformin) or/and intraperitoneal injection (solamargine) for up to 27 days. We observed that, compared to the control group, the metfromin- or solamargine-treated mice demonstrated a significant growthinhibitory effect as assessed by the Xenogen IVIS200 System (Fig. 6A). More importantly, a further inhibitory outcome was observed in the combination treatment group (Fig. 6A). In addition, we found a substantial reduction of the tumor weight and size in the metformin-, or solamargine-treated groups as compared to that in the control group (Fig. 6B-D). As expected, a further inhibitory effect was noticed in the combination group (Fig. 6B-D). Moreover, consistent with the results from that in the in vitro data, the reduced expression of SP1, whereas increase in FOXO3a and IGFBP1 proteins from fresh tumors harvested from the above experiment were observed in the metformin-, or solamargine-treated groups as compared to that in the control group (Fig. 6E). Note that the combination treatment showed even greater effects (Fig. 6E). As expected, the immunohistochemistry results also unveiled the similar results (Fig. 6F). 
Fig. 5. Interaction between the FOX03a and SP1 contributed to the induction of IGFBP1 expression by solamargine, and overexpression of IGFBP1 restored the effect of solamargine on cell growth inhibition. A, Cellular protein was isolated from A549 and PC9 cells transfected with control or FOXO3a SiRNAs for up to $30 \mathrm{~h}$ before exposing the cells to SM $(6 \mu \mathrm{M})$ for an additional 24 h. Afterwards, the expressions of FOXO3a and IGFBP1 proteins were detected by Western blot. B,

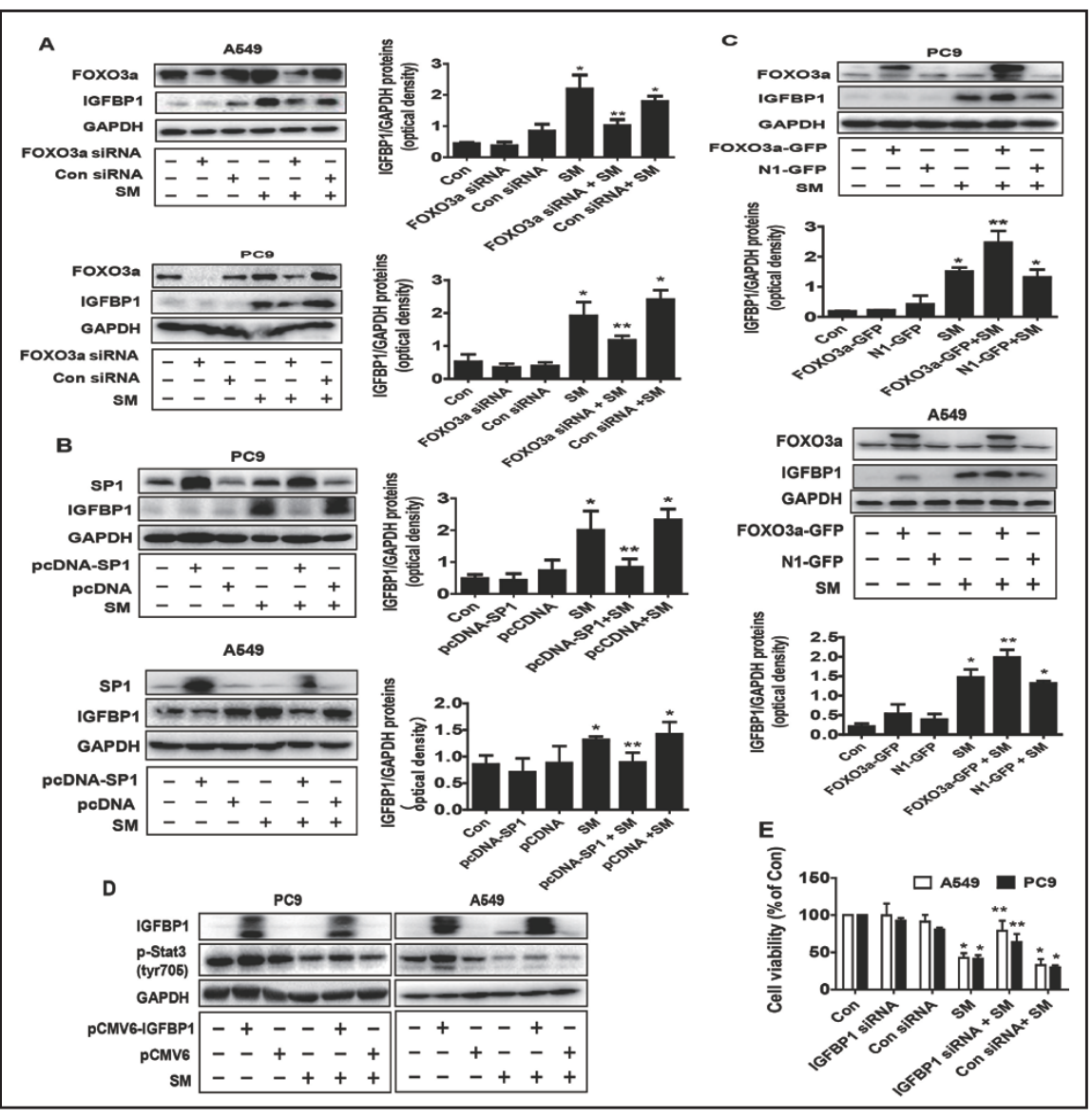
A549 and PC9 cells

were transfected with control or SP1 overexpression vectors for $24 \mathrm{~h}$ before exposing the cells to SM for an additional $24 \mathrm{~h}$. Afterwards, SP1 and IGFBP1 protein expressions were determined by Western blot. C, Cellular protein was isolated from A549 and PC9 cells transfected with control or FOXO3a expression vectors for up to $30 \mathrm{~h}$ before exposing the cells to SM $(6 \mu \mathrm{M})$ for an additional $24 \mathrm{~h}$. Afterwards, the expressions of FOXO3a and IGFBP1 proteins were detected by Western blot. D, Cellular protein was isolated from A549 and PC9 cells transfected with control or IGFBP1 expression vectors for up to $30 \mathrm{~h}$ before exposing the cells to SM $(6 \mu \mathrm{M})$ for an additional $24 \mathrm{~h}$. Afterwards, the phosphorylation of Stat 3 and expression of IGFBP1 protein were detected by Western blot. GAPDH was used as loading control. E, A549 and PC9 cells were transfected with control or IGFBP1 siRNAs for $24 \mathrm{~h}$ before exposing the cells to SM (6 $\mu \mathrm{M})$ for an additional $24 \mathrm{~h}$. Afterwards, the cells were collected and processed for MTT assay as described in the Materials and Methods section. *Indicates significant difference as compared to the untreated control group $(\mathrm{P}<0.05)$; ${ }^{* *}$ Indicates significance of combination treatment as compared to SM alone $(\mathrm{P}<0.05)$.

\section{Discussion}

In this study, we presented several lines of evidence from protein expression regulation, proliferation, and xenograft experiments in vivo to demonstrate the critical role of IGFBP1 as a tumor suppressor in mediating the anti-cancer effects of solamargine and metformin. Our results indicated that inactivation of Stat3, followed by interaction and regulation of transcription factors FOXO3a and SP1 contributed to the induction of IGFBP1 expression by solamargine in vitro and in vivo.

Growing interest has focused on the use of natural plants to reduce the incidence and mortality of cancer, leading to encouraging results. Steroidal glycoalkaloids are naturally occurring nitrogen containing secondary metabolites found in plants of the Solanaceae family. Solamargine, a steroidal alkaloid glycoside extracted from the traditional Chinese herb Sola- 
Fig. 6. In vivo anti-tumor efficacy of solamargine in mice. Mice $(n=9 /$ group) were divided to 4 groups [Con (saline), metformin (Met, 250 $\mathrm{mg} / \mathrm{kg}$ ), solamargine (SM, $8 \mathrm{mg} /$ $\mathrm{kg}$ ), and SM plus Met] and SM was given at the $8^{\text {th }}$ day after tumor cells via intraperitoneal injection for up to 27 days. A, the xenografts were assessed by in vivo bioluminescence imaging at the initial and end of the experiments (on day 8 and $27)$. The tumor growth was monitored by injecting luciferin in the mice followed by measuring bioluminescence using IVIS Imaging System. Imaging and quantification of signals were controlled by the acquisition and analysis software living image as described in the Materials and Methods section. Representative images are shown. B and $\mathrm{C}$, The xenografts were harvested on day 27, and the volume and weight of tumors were measured. D, The photographs of vehicle- and drugs-treated xenografts derived from nude mice are shown. E-F, At the end of the experiments, xenografted tumors were isolated from individual animals and the corresponding lysates were processed and detected FOXO3a, SP1 and IGFBP1 by Western blot with the indicated antibodies and Immunohistochemistry as described in the Materials and Methods sections. Scale bar $50 \mu \mathrm{M}$. GAPDH was used as loading control for Western blot. The bar graphs represented the tumor weight and volume of mice results indicated as mean $\pm \mathrm{SD}$. *Indicates the significant difference from the untreated control $(\mathrm{p}<0.05) . \mathrm{G}$, The diagram shows that solamargine inhibits growth of NSCLC cells through inactivation of Stat3, followed by reduction of SP1 and induction of FOXO3a; this ultimately

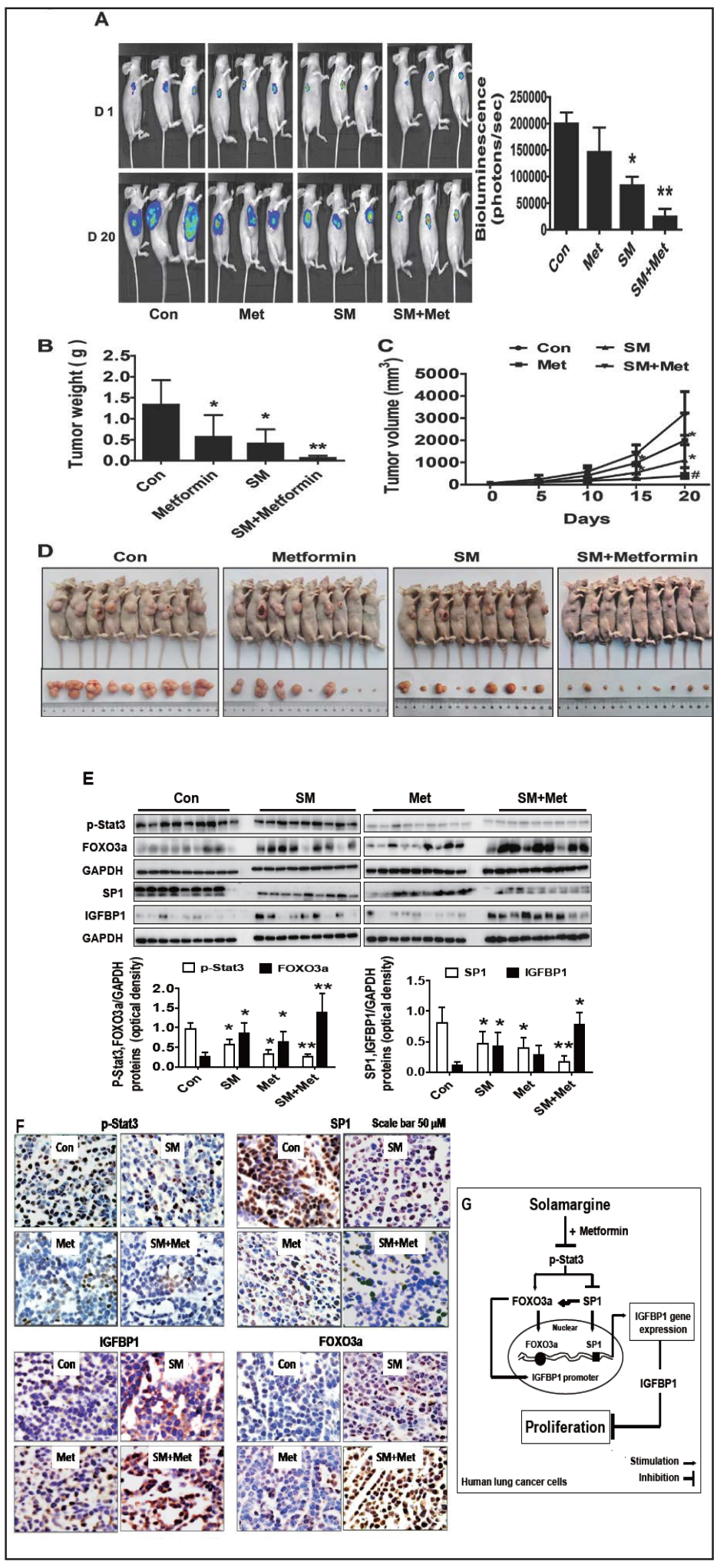

induces the expression of IGFBP1 gene. There is synergy of combination of solamargine and metformin. Intriguingly, the interactions between FOXO3a and SP1 are required in regulating IGFBP1 gene expression in response to solamargine. Moreover, silencing of IGFBP1 abrogates solamargine-inhibited growth of NSCLC cells. 
num incanum, has been reported to have various pharmacological functions including anticancer activities $[22,50,51]$. Although there were important discoveries revealed by other studies indicated multiple signaling pathways and molecular genes or proteins that involved in the anti-tumor responses of solamargine, the in-depth molecular mechanisms by which this agent in inhibition of tumor growth still remained to be elucidated. Consistent with our previous report [21], the current results further confirmed the anti-lung cancer effects of solamargine and suggested a potential therapeutic modality in lung cancer.

Our findings indicated that inactivation of Stat 3 was involved in the effect of solamargine on anti-lung cancer growth. As a cytoplasmic transcription factor that modulates the transcription of a variety of genes and regulates several biological functions including proliferation, differentiation, angiogenesis, progression and metastasis, constitutive activation of Stat3 was involved in oncogenic transformation and progression in several cancer types [52-54]. We observed that inactivation of Stat3 phosphorylation (Tyr705) was occurred in the anti-lung cancer effect of solamargines. However, whether or not solamargines could affect other phosphorylation sites of Stat3 still remained to be determined. The phosphoryation (Tyr705) of Stat3 was reported to interacted with phosphatidylinositol 3-kinase (PI3-K)-induced oncogenic transformation and growth in both non-cancer and cancer cell types [52-55]. Nevertheless, we reasoned that more experiments are required to further elucidate the true role of Stat3 phosphorylation affected by solamargines. Our results also suggested that inactivation of Stat3 was required in mediating the regulation of two important downstream effectors SP1 and FOX03, thereby increasing expression of IGFBP1 and cell growth inhibition in our study. In line with this, inactivation and inhibition of Stat3 have been shown in other studies involving the inhibition of cancer cell growth and survival $[5,56,57]$ suggesting that targeting this could be potential in cancer treatment.

As a bona fide pleiotropic tumor suppressor, FOXO3 negatively regulates cancer cell proliferation and progression by regulating the expression of genes involved in apoptosis, cell cycle, oxidative stress response, and angiogenesis. Also, transcription factor SP1 is a well known tumor promoter and is involved in the variety of biological functions including cancer cell growth. We demonstrated that both FOXO3a and SP1 were downstream effecters of Stat3 and that inactivation of Stat 3 was involved in the induction of FOXO3a and reduction of SP1 in the effect of solamargine in this process. Regulation of FOXO3a and SP1 linked to the Stat3 signaling and involved in a number of cellular functions, such as tumorigenesis, progression, growth, and metastasis, has been shown in other studies $[44,45,58]$. The induction of FOXO3a and inhibition of SP1, and interaction between FOXO3a and SP1 have also been reported to be associated with regulation of other genes, thereby controlling cancer cell survival in other studies, this demonstrates the critical roles of these transcription factors in these processes [59-61]. For example, high expression of SP1 was observed in the ovarian cancer cells and that the SP1 inhibitor was found to enhance the response of cisplatin on growth inhibition [59]. Also, cetuximab, a monoclonal antibody against epidermal growth factor receptor (EGF-R), stimulated FOXO3a expression and promoted its nuclear translocation, leading to induction of apoptosis and inhibition of proliferation in colorectal cancer cells [60]. Thus, FOXO3a and SP1 could be used as potential targets in treatment modality of cancer.

We also demonstrated an important role of SP1 and FOXO3a in mediating the effect of solamargine on IGFBP1 expression. A number of direct and indirect links between FOXO, SP1 and IGFBP1 have already been uncovered. These results reveal a complex mechanism axis, which have been involved in the regulation of other gene expressions, biological functions and tumor growth [62-64]. As common ubiquitous transcription factor that binds to GC-rich motifs of several gene promoters, SP1 was involved in many cellular functions, such as growth, differentiation, and progression through regulation of several relevant genes [65]. Report found that SP1-like binding site in IGFBP1 promoter region was required for the regulation of IGFBP1 gene expression in human endometrial stromal cells [47]. Consistent with this, our findings suggested that reduction of SP1 may be required in the upregulation of IGFBP1 expression by solamargine. While limited information have been shown the direct links of FOXO3a and IGFBP1, our results demonstrated that induction of FOXO3a was involved in 
the subsequently increase in IGFBP1 expression. Nevertheless, more experiments are still required to determine if there is a physical binding between SP1 and FOXO3a, which might influence solamargine-increased IGFBP1 expression and the overall anti-lung cancer effects.

Interestingly, we found that increased expression of IGFBP1 stimulated the solamargineinhibited lung cancer cell proliferation. In addition to inhibiting IGF receptors, IGFBP1 also suppress cancer cell proliferation, motility and progression via regulating several important downstream molecules or targets $[27,66,67]$, this highlights a tumor suppressor role. Consistent with these, our results suggested that induction of IGFBP1 was required in stimulating the solamargine-inhibited NSCLC growth. However, opposite results were also observed in other cancer types, such as prostate cancer [33,34] and endometrial cancer [35]. Thus, the true functions of IGFBP1 acting as a tumor suppressor or oncogene may depend upon the capacity of environmental context, and agents exposed, which required to be determined. Our study suggested that IGFBP1 may be considered as a novel potential biomarker for lung cancer growth and progression, and that increased IGFBP1 could add compatible with current treatment regimes for lung cancer.

More importantly, our results suggested a possibility of the synergy of solamargine in combination with metformin. Metformin, an oral biguanide commonly used for treating type II diabetes, has been reported to possess anti-cancer properties in a variety of tumor types using alone and combination with other agents, the latter showed greater effects $[68,69]$. However, there was less information available regarding the combination of solamargine and metformin in cancer treatment. We previously observed that metformin facilitated the effect of solamargine on castration-resistant prostate cancer cells [42]. We reason that further understanding the potential molecular mechanisms of this combination effect may unveil greater potency and offer a possible new strategy in inhibition of lung cancer growth with minimal adverse outcomes and maximal efficiency. Thus, more studies are required to explore the in-depth mechanism and clinical significance of the potential synergy of solamargine in combination with metformin.

As expected, our in vivo data were consistent with the findings from that in vitro, confirming the effect of solamargine on lung cancer growth inhibition and regulation of SP1, FOXO3a and IGFBP1 expression in the presence or absence of metformin. The doses of solamargine used were based on our previous reports [22, 42] and other study [70]. In spite of this, future experiments are required to further determine the critical role of IGFBP1 in this process using cells stable transfected with shRNA and exogenously expression vector containing coding region of IGFBP1 gene in animal models.

Collectively, our results show that solamargine inhibits growth of NSCLC cells through inactivation of Stat3, followed by reduction of SP1 and induction of FOXO3a; this ultimately induces the expression of IGFBP1 gene. There is synergy of solamargine in combination with metformin. Intriguingly, the interaction between FOXO3a and SP1 are required in regulating IGFBP1 gene expression in response to solamargine. Moreover, silencing of IGFBP1 abrogates solamargine-inhibited growth of NSCLC cells (Fig. 6F). This study unveils an additional novel mechanism by which solamargine alone or/and in combination with metformin inhibit growth of human lung cancer cells and provides new insights into IGFBP1-mediated cellular responses toward human lung cancer therapeutics. The true impact of these molecules above in the clinical arena in lung cancer patients, especially the activation/expressions of these molecules link to clinical outcomes, such as acting as potential biomarkers and therapeutic targets, still required to be determined in the future with more in-depth experimental approaches.

\section{Acknowledgements}

We thank Dr. Frank M. J. Jacobs (Rudolf Magnus Institute of Neuroscience, University Medical Center, Utrecht, Netherlands) for providing FOX3a expression vector, and Dr. Thomas E. Eling (National Institute of Environmental Health Sciences, USA) for providing SP1 


\section{Cellular Physiology Cell Physiol Biochem 2017;43:2310-2326

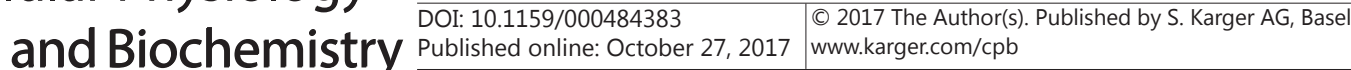 \\ Tang et al.: Combination of Solamargine and Metformin Strengthens IGFBP1 Gene Expression}

expression vectors. This work was supported in part by the grants from the National Nature Scientific Foundation of China (81272614, 81403216, 81703551, 81774067), the Science and Technology Program of Guangzhou (201607010385), the Discipline of Integrated Chinese and Western Medicine in Guangzhou University of Chinese Medicine (A1-AfD018161Z1513), the Special Science and Technology Join fund from Guangdong Provincial Department of Science and Technology-Guangdong Academy of Traditional Chinese Medicine (2012A032500011, 2014A020221024,) and The Specific Research Fund for TCM Science and Technology of Guangdong Provincial Hospital of Chinese Medicine (YK2013B2N13, YN2015MS19).

\section{Disclosure Statement}

The authors declare that they have no competing interests.

\section{References}

1 Siegel RL, Miller KD, Jemal A: Cancer statistics, 2016. CA Cancer J Clin 2016;66:7-30.

2 Chang GC, Chen KC, Yang TY, Yin MC, Lin CP, Kuo BI, Hsu JY: Activity of gefitinib in advanced non-small-cell lung cancer with very poor performance status. Invest New Drugs 2005;23:73-77.

3 Kim BH, Yi EH, Ye SK: Signal transducer and activator of transcription 3 as a therapeutic target for cancer and the tumor microenvironment. Arch Pharm Res 2016;39:1085-1099.

4 Yang XW, Li L, Hou GJ, Yan XZ, Xu QG, Chen L, Zhang BH, Shen F: Stat3 overexpression promotes metastasis in intrahepatic cholangiocarcinoma and correlates negatively with surgical outcome. Oncotarget 2017;8:7710-7721.

5 Miyata H, Ashizawa T, Iizuka A, Kondou R, Nonomura C, Sugino T, Urakami K, Asai A, Hayashi N, Mitsuya K, Nakasu Y, Yamaguchi K, Akiyama Y: Combination of a stat3 inhibitor and an mtor inhibitor against a temozolomide-resistant glioblastoma cell line. Cancer Genomics Proteomics 2017;14:83-91.

6 Saengboonmee C, Seubwai W, Cha'on U, Sawanyawisuth K, Wongkham S, Wongkham C: Metformin exerts antiproliferative and anti-metastatic effects against cholangiocarcinoma cells by targeting stat 3 and $\mathrm{nf}-\mathrm{kb}$. Anticancer Res 2017;37:115-123.

7 Chang L, Gong F, Cai H, Li Z, Cui Y: Combined rnai targeting human stat3 and adam9 as gene therapy for non-small cell lung cancer. Oncol Lett 2016;11:1242-1250.

8 Huang H, Tindall DJ: Dynamic foxo transcription factors. J Cell Sci 2007;120:2479-2487.

-9 Yu S, Yu Y, Zhang W, Yuan W, Zhao N, Li Q, Cui Y, Wang Y, Li W, Sun Y, Liu T: Foxo3a promotes gastric cancer cell migration and invasion through the induction of cathepsin l. Oncotarget 2016;7:34773-34784.

10 Bigarella CL, Li J, Rimmele P, Liang R, Sobol RW, Ghaffari S: Foxo3 transcription factor is essential for protecting hematopoietic stem and progenitor cells from oxidative DNA damage. J Biol Chem 2017;292:3005-3015.

11 Chen Q, Chen X, Han C, Wang Y, Huang T, Du Y, Dong Z: Fgf-2 transcriptionally down-regulates the expression of bnip3l via pi3k/akt/foxo3a signaling and inhibits necrosis and mitochondrial dysfunction induced by high concentrations of hydrogen peroxide in h9c2 cells. Cell Physiol Biochem 2016;40:16781691.

12 Ananda Sadagopan SK, Mohebali N, Looi CY, Hasanpourghadi M, Pandurangan AK, Arya A, Karimian H, Mustafa MR: Forkhead box transcription factor (foxo3a) mediates the cytotoxic effect of vernodalin in vitro and inhibits the breast tumor growth in vivo. J Exp Clin Cancer Res 2015;34:147.

13 Zheng F, Wu J, Zhao S, Luo Q, Tang Q Yang L, Li L, Wu W, Hann SS: Baicalein increases the expression and reciprocal interplay of runx3 and foxo3a through crosstalk of ampkalpha and mek/erk1/2 signaling pathways in human non-small cell lung cancer cells. J Exp Clin Cancer Res 2015;34:41.

14 Kops GJ, Dansen TB, Polderman PE, Saarloos I, Wirtz KW, Coffer PJ, Huang TT, Bos JL, Medema RH, Burgering BM: Forkhead transcription factor foxo3a protects quiescent cells from oxidative stress. Nature 2002;419:316-321. 


\section{Cellular Physiology Cell Physiol Biochem 2017;43:2310-2326

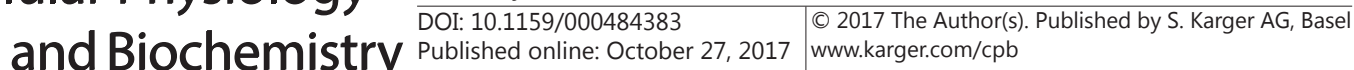

15 Li Z, Zhang H, Chen Y, Fan L, Fang J: Forkhead transcription factor foxo3a protein activates nuclear factor kappab through b-cell lymphoma/leukemia 10 (bcl10) protein and promotes tumor cell survival in serum deprivation. J Biol Chem 2012;287:17737-17745.

-16 Munari CC, de Oliveira PF, Campos JC, Martins Sde P, Da Costa JC, Bastos JK, Tavares DC: Antiproliferative activity of solanum lycocarpum alkaloidic extract and their constituents, solamargine and solasonine, in tumor cell lines. J Nat Med 2014;68:236-241.

17 Zhou Y, Tang Q, Zhao S, Zhang F, Li L, Wu W, Wang Z, Hann S: Targeting signal transducer and activator of transcription 3 contributes to the solamargine-inhibited growth and -induced apoptosis of human lung cancer cells. Tumour Biol 2014;35:8169-8178.

18 Friedman M: Chemistry and anticarcinogenic mechanisms of glycoalkaloids produced by eggplants, potatoes, and tomatoes. J Agric Food Chem 2015;63:3323-3337.

19 Cui CZ, Wen XS, Cui M, Gao J, Sun B, Lou HX: Synthesis of solasodine glycoside derivatives and evaluation of their cytotoxic effects on human cancer cells. Drug Discov Ther 2012;6:9-17.

20 Chen Y, Teng L, Liu W, Cao Y, Ding D, Wang W, Chen H, Li C, An R: Identification of biological targets of therapeutic intervention for clear cell renal cell carcinoma based on bioinformatics approach. Cancer Cell Int 2016;16:16.

21 Chen Y, Tang Q, Wu J, Zheng F, Yang L, Hann SS: Inactivation of pi3-k/akt and reduction of sp1 and p65 expression increase the effect of solamargine on suppressing ep4 expression in human lung cancer cells. J Exp Clin Cancer Res 2015;34:154.

-22 Chen Y, Tang Q, Xiao Q Yang L, Hann SS: Targeting ep4 downstream c-jun through erk1/2-mediated reduction of dnmt1 reveals novel mechanism of solamargine-inhibited growth of lung cancer cells. J Cell Mol Med 2017;21:222-233.

-23 Major JM, Laughlin GA, Kritz-Silverstein D, Wingard DL, Barrett-Connor E: Insulin-like growth factor-i and cancer mortality in older men. J Clin Endocrinol Metab 2010;95:1054-1059.

24 Kashyap MK: Role of insulin-like growth factor-binding proteins in the pathophysiology and tumorigenesis of gastroesophageal cancers. Tumour Biol 2015;36:8247-8257.

25 Hsieh DJ, Kuo WW, Lai YP, Shibu MA, Shen CY, Pai P, Yeh YL, Lin JY, Viswanadha VP, Huang CY: 17 betaestradiol and/or estrogen receptor beta attenuate the autophagic and apoptotic effects induced by prolonged hypoxia through hif-1alpha-mediated bnip3 and igfbp-3 signaling blockage. Cell Physiol Biochem 2015;36:274-284.

-26 Kim JJ, Taylor HS, Akbas GE, Foucher I, Trembleau A, Jaffe RC, Fazleabas AT, Unterman TG: Regulation of insulin-like growth factor binding protein-1 promoter activity by fkhr and hoxa10 in primate endometrial cells. Biol Reprod 2003;68:24-30.

27 Baxter RC: Igf binding proteins in cancer: Mechanistic and clinical insights. Nat Rev Cancer 2014;14:329341.

28 Ammoun S, Schmid MC, Zhou L, Ristic N, Ercolano E, Hilton DA, Perks CM, Hanemann CO: Insulin-like growth factor-binding protein-1 (igfbp-1) regulates human schwannoma proliferation, adhesion and survival. Oncogene 2012;31:1710-1722.

-29 Figueroa JA, Sharma J, Jackson JG, McDermott MJ, Hilsenbeck SG, Yee D: Recombinant insulin-like growth factor binding protein-1 inhibits igf-i, serum, and estrogen-dependent growth of mcf-7 human breast cancer cells. J Cell Physiol 1993;157:229-236.

30 Park JH, Rasch MG, Qiu J, Lund IK, Egeblad M: Presence of insulin-like growth factor binding proteins correlates with tumor-promoting effects of matrix metalloproteinase 9 in breast cancer. Neoplasia 2015;17:421-433.

31 Yang LJ, Tang Q, Wu J, Chen Y, Zheng F, Dai Z, Hann SS: Inter-regulation of igfbp1 and foxo3a unveils novel mechanism in ursolic acid-inhibited growth of hepatocellular carcinoma cells. J Exp Clin Cancer Res 2016;35:59.

-32 Tang Q, Wu J, Zheng F, Hann SS, Chen Y: Emodin increases expression of insulin-like growth factor binding protein 1 through activation of mek/erk/ampkalpha and interaction of ppargamma and sp1 in lung cancer. Cell Physiol Biochem 2017;41:339-357.

-33 Cao Y, Nimptsch K, Shui IM, Platz EA, Wu K, Pollak MN, Kenfield SA, Stampfer MJ, Giovannucci EL: Prediagnostic plasma igfbp-1, igf-1 and risk of prostate cancer. Int J Cancer 2015;136:2418-2426. 


\section{Cellular Physiology Cell Physiol Biochem 2017;43:2310-2326 and Biochemistry \begin{tabular}{l|l} 
DOI: 10.1159/000484383 2017 The Author(s). Published by S. Karger AG, Basel \\
www.karger.com/cpb
\end{tabular}

34 Sharma J, Gray KP, Evan C, Nakabayashi M, Fichorova R, Rider J, Mucci L, Kantoff PW, Sweeney CJ: Elevated insulin-like growth factor binding protein-1 (igfbp-1) in men with metastatic prostate cancer starting androgen deprivation therapy (adt) is associated with shorter time to castration resistance and overall survival. Prostate 2014;74:225-234.

-35 Shafiee MN, Seedhouse C, Mongan N, Chapman C, Deen S, Abu J, Atiomo W: Up-regulation of genes involved in the insulin signalling pathway (igf1, pten and igfbp1) in the endometrium may link polycystic ovarian syndrome and endometrial cancer. Mol Cell Endocrinol 2016;424:94-101.

-36 Gong J, Shen S, Yang Y, Qin S, Huang L, Zhang H, Chen L, Chen Y, Li S, She S, Yang M, Ren H, Hu H: Inhibition of fasn suppresses migration, invasion and growth in hepatoma carcinoma cells by deregulating the hif1alpha/igfbp1 pathway. Int J Oncol 2017;50:883-892.

37 Zheng F, Tang Q Wu J, Zhao S, Liang Z, Li L, Wu W, Hann S: P38alpha mapk-mediated induction and interaction of foxo3a and p53 contribute to the inhibited-growth and induced-apoptosis of human lung adenocarcinoma cells by berberine. J Exp Clin Cancer Res 2014;33:36.

38 Hann SS, Chen J, Wang Z, Wu J, Zheng F, Zhao S: Targeting ep4 by curcumin through cross talks of ampdependent kinase alpha and p38 mitogen-activated protein kinase signaling: The role of pgc-1alpha and sp1. Cell Signal 2013;25:2566-2574.

-39 Wen Q, Duan X, Liao R, Little P, Gao G, Jiang H, Lalit S, Quirion R, Zheng W: Characterization of intracellular translocation of forkhead transcription factor o (foxo) members induced by ngf in pc12 cells. Neurosci Lett 2011;498:31-36.

40 Kambe A, Iguchi G, Moon Y, Kamitani H, Watanabe T, Eling TE: Regulation of ep4 expression via the sp-1 transcription factor: Inhibition of expression by anti-cancer agents. Biochim Biophys Acta 2008;1783:1211-1219.

-41 Storozhuk Y, Hopmans SN, Sanli T, Barron C, Tsiani E, Cutz JC, Pond G, Wright J, Singh G, Tsakiridis T: Metformin inhibits growth and enhances radiation response of non-small cell lung cancer (nsclc) through atm and ampk. Br J Cancer 2013;108:2021-2032.

-42 Xiang S, Zhang Q Tang Q Zheng F, Wu J, Yang L, Hann SS: Activation of ampkalpha mediates additive effects of solamargine and metformin on suppressing muc1 expression in castration-resistant prostate cancer cells. Sci Rep 2016;6:36721.

43 Jalving M, Gietema JA, Lefrandt JD, de Jong S, Reyners AK, Gans RO, de Vries EG: Metformin: Taking away the candy for cancer? Eur J Cancer 2010;46:2369-2380.

44 Huang C, Xie K: Crosstalk of sp1 and stat3 signaling in pancreatic cancer pathogenesis. Cytokine Growth Factor Rev 2012;23:25-35.

45 Oh HM, Yu CR, Dambuza I, Marrero B, Egwuagu CE: Stat3 protein interacts with class o forkhead transcription factors in the cytoplasm and regulates nuclear/cytoplasmic localization of foxo1 and foxo3a proteins in cd4(+) t cells. J Biol Chem 2012;287:30436-30443.

-46 Katanasaka Y, Kodera Y, Yunokawa M, Kitamura Y, Tamura T, Koizumi F: Synergistic anti-tumor effects of a novel phosphatidyl inositol-3 kinase/mammalian target of rapamycin dual inhibitor bgt226 and gefitinib in non-small cell lung cancer cell lines. Cancer Lett 2014;347:196-203.

47 Gao JG, Mazella J, Tseng L: Activation of the human igfbp-1 gene promoter by progestin and relaxin in primary culture of human endometrial stromal cells. Mol Cell Endocrinol 1994;104:39-46.

48 Yalley A, Schill D, Hatta M, Johnson N, Cirillo LA: Loss of interdependent binding by the foxo1 and foxa1/ a2 forkhead transcription factors culminates in perturbation of active chromatin marks and binding of transcriptional regulators at insulin-sensitive genes. J Biol Chem 2016;291:8848-8861.

49 Gan L, Han Y, Bastianetto S, Dumont Y, Unterman TG, Quirion R: Foxo-dependent and -independent mechanisms mediate sirt1 effects on igfbp-1 gene expression. Biochem Biophys Res Commun 2005;337:1092-1096.

50 Xie X, Zhu H, Yang H, Huang W, Wu Y, Wang Y, Luo Y, Wang D, Shao G: Solamargine triggers hepatoma cell death through apoptosis. Oncol Lett 2015;10:168-174.

-51 Al Sinani SS, Eltayeb EA, Coomber BL, Adham SA: Solamargine triggers cellular necrosis selectively in different types of human melanoma cancer cells through extrinsic lysosomal mitochondrial death pathway. Cancer Cell Int 2016;16:11.

-52 Kim E, Kim M, Woo DH, Shin Y, Shin J, Chang N, Oh YT, Kim H, Rheey J, Nakano I, Lee C, Joo KM, Rich JN, Nam DH, Lee J: Phosphorylation of ezh2 activates stat3 signaling via stat3 methylation and promotes tumorigenicity of glioblastoma stem-like cells. Cancer Cell 2013;23:839-852. 


\section{Cellular Physiology Cell Physiol Biochem 2017;43:2310-2326 and Biochemistry \begin{tabular}{c|c|c|} 
DOI: 10.1159/000484383 \\
Published online: October 27, 2017 & $\begin{array}{l}\text { O } 2017 \text { The Author(s). Published by S. Karger AG, Basel } \\
\text { www.karger.com/cpb }\end{array}$
\end{tabular}}

Tang et al.: Combination of Solamargine and Metformin Strengthens IGFBP1 Gene Expression

53 Vogt PK, Hart JR: Pi3k and stat3: A new alliance. Cancer Discov 2011;1:481-486.

$54 \mathrm{Hu}$ W, Jin P, Liu W: Periostin contributes to cisplatin resistance in human non-small cell lung cancer a549 cells via activation of stat3 and akt and upregulation of survivin. Cell Physiol Biochem 2016;38:1199-1208.

55 Pramanik KC, Fofaria NM, Gupta P, Ranjan A, Kim SH, Srivastava SK: Inhibition of beta-catenin signaling suppresses pancreatic tumor growth by disrupting nuclear beta-catenin/tcf-1 complex: Critical role of stat3. Oncotarget 2015;6:11561-11574.

-56 Airoldi I, Cocco C, Sorrentino C, Angelucci D, Di Meo S, Manzoli L, Esposito S, Ribatti D, Bertolotto M, Iezzi L, Natoli C, Di Carlo E: Interleukin-30 promotes breast cancer growth and progression. Cancer Res 2016;76:6218-6229.

57 Zhang T, Li S, Li J, Yin F, Hua Y, Wang Z, Lin B, Wang H, Zou D, Zhou Z, Xu J, Yi C, Cai Z: Natural product pectolinarigenin inhibits osteosarcoma growth and metastasis via shp-1-mediated stat3 signaling inhibition. Cell Death Dis 2016;7:e2421.

-58 Quotti Tubi L, Canovas Nunes S, Brancalion A, Doriguzzi Breatta E, Manni S, Mandato E, Zaffino F, Macaccaro P, Carrino M, Gianesin K, Trentin L, Binotto G, Zambello R, Semenzato G, Gurrieri C, Piazza F: Protein kinase ck2 regulates akt, nf-kappab and stat3 activation, stem cell viability and proliferation in acute myeloid leukemia. Leukemia 2017;31:292-300.

59 Sankpal UT, Ingersoll SB, Ahmad S, Holloway RW, Bhat VB, Simecka JW, Daniel L, Kariali E, Vishwanatha JK, Basha R: Association of sp1 and survivin in epithelial ovarian cancer: Sp1 inhibitor and cisplatin, a novel combination for inhibiting epithelial ovarian cancer cell proliferation. Tumour Biol 2016;37:14259-14269.

60 Marzi L, Combes E, Vie N, Ayrolles-Torro A, Tosi D, Desigaud D, Perez-Gracia E, Larbouret C, Montagut C, Iglesias M, Jarlier M, Denis V, Linares LK, Lam EW, Martineau P, Del Rio M, Gongora C: Foxo3a and the mapk p38 are activated by cetuximab to induce cell death and inhibit cell proliferation and their expression predicts cetuximab efficacy in colorectal cancer. Br J Cancer 2016;115:1223-1233.

-61 Deng X, Zhang W, I OS, Williams JB, Dong Q Park EA, Raghow R, Unterman TG, Elam MB: Foxo1 inhibits sterol regulatory element-binding protein-1c (srebp-1c) gene expression via transcription factors sp1 and srebp-1c. J Biol Chem 2012;287:20132-20143.

62 Chen YJ, Chen CC, Li TK, Wang PH, Liu LR, Chang FY, Wang YC, Yu YH, Lin SP, Mersmann HJ, Ding ST: Docosahexaenoic acid suppresses the expression of foxo and its target genes. J Nutr Biochem 2012;23:1609-1616.

63 Wu CH, Chen S, Shortreed MR, Kreitinger GM, Yuan Y, Frey BL, Zhang Y, Mirza S, Cirillo LA, Olivier M, Smith LM: Sequence-specific capture of protein-DNA complexes for mass spectrometric protein identification. PLoS One 2011;6:e26217.

64 Gao J, Mazella J, Tseng L: Hox proteins activate the igfbp-1 promoter and suppress the function of hpr in human endometrial cells. DNA Cell Biol 2002;21:819-825.

65 Beishline K, Azizkhan-Clifford J: Sp1 and the 'hallmarks of cancer'. FEBS J 2015;282:224-258.

66 Dai B, Ruan B, Wu J, Wang J, Shang R, Sun W, Li X, Dou K, Wang D, Li Y: Insulin-like growth factor binding protein-1 inhibits cancer cell invasion and is associated with poor prognosis in hepatocellular carcinoma. Int J Clin Exp Pathol 2014;7:5645-5654.

67 Geis T, Popp R, Hu J, Fleming I, Henke N, Dehne N, Brune B: Hif-2alpha attenuates lymphangiogenesis by up-regulating igfbp1 in hepatocellular carcinoma. Biol Cell 2015;107:175-188.

68 Xu Y, Lu S: Metformin inhibits esophagus cancer proliferation through upregulation of usp7. Cell Physiol Biochem 2013;32:1178-1186.

69 Chung EJ, Do EJ, Kim SY, Cho EA, Kim DH, Pak S, Hwang SW, Lee HJ, Byeon JS, Ye BD, Yang DH, Park SH, Yang SK, Kim JH, Myung SJ: Combination of metformin and vsl\#3 additively suppresses western-style diet induced colon cancer in mice. Eur J Pharmacol 2017;794:1-7.

-70 Tang Z, Zhang Y, Li N, Xu L, Zhao B, Xiao W, Wang Z, Bi Y: [extraction, purification technology and antineoplastic effects of solamargine]. Zhongguo Zhong Yao Za Zhi 2011;36:2192-2195. 